\title{
An Overview of Hydrogen Production Technologies of Water Electrolysis
}

\author{
Imperiyka M. H. ${ }^{1}$, Rahuma, M. N. ${ }^{2}$, Eman B.A \\ ${ }^{1}$ Faculty of Arts and Sciences, Kufra Campus, University of Benghazi, AlKufrah, Libya \\ ${ }^{2}$ Department of Chemistry, University of Benghazi, Libya \\ ${ }^{3}$ Department of Energy Technology, The Libyan Academy Benghazi, Libya
}

\begin{abstract}
This review provides an overview of some important investigations performed on the development of hydrogen production. In the near future, hydrogen will become an important source which may be able to solve local problems also connected with air quality. Hydrogen-propelled transport is being established and is utilized in the industry. Hydrogen is abundantly present all over universe and can be obtained from different resources, renewable or not. Sources of hydrogen energy are coal and biomass, oil, natural gas, algae and alcohols, water electrolysis, PV-electrolysis, wind-electrolysis and geothermal energy electrolysis. In particular, hydrogen can be generated from water electrolysis using all those processes that can give the required $1.23 \mathrm{~V}$ potential. Electrolysis reveals itself as the cleanest method to generate hydrogen, when the required electricity is derived from renewable energy sources. This work provides also basic information, particularly about the main research lines and some factors affecting hydrogen production in electrolysis process.
\end{abstract}

Keywords: hydrogen production; hydrogen source; electrolysis; water; renewable energy.

\section{Introduction}

Hydrogen is the first element on the periodic table, making it the lightest element on Earth. Since hydrogen gas is so light, it rises in the atmosphere and is therefore rarely found in its elementary form, $\mathrm{H}_{2}$. In a flame of hydrogen gas, burning in air, hydrogen can react with oxygen to form water (Altork and et al. 2010). During the twentieth century the world has undergone a series of scientific and technological revolutions that led to a significant increase in the role of energy resource as key factor in the economic and social development. The modern civilization has often been based on the utilization of fossil fuels, and today petroleum and natural gas meet about $80 \%$ of the world energy demand. However, the ever increasing consumption of fossil fuels reserves will lead to their depletion and to the strong environmental impact well known in terms of $\mathrm{CO}_{2}$ emissions (Hegazy 2005). Every step of fuel evolution represented a progress in human civilization and development, thus reaching a large-scale application of hydrogen fuel will elevate the human quality life to higher horizons. Researchers are developing a wide range of technologies to produce hydrogen economically from a variety of resources in environmentally friendly ways (Contreras 2007). Hydrogen is sa deredisnocthe cleanest fuel in the world, and has a heating value three times higher than petroleum. In contrast, hydrogen is not a natural source, but a man-made fuel; hence, hydrogen bears a manufacture price, which leads it costing three times higher than the petroleum counterpart (Zhou; 2005). However, it must always be remembered that burning fossil fuels leads to the alteration of the weather, atmosphere and climate in an unusual manner (Richard 2004). Due to the diminution of fossil fuels and the global warming, society is commonly considering renewably produced hydrogen as an alternative clean fuel for transportation. The use of hydrogen as an energy power is a key element in developing clean fossil fuel alternatives (Ana 2006). In practice, only fossil fuels processing and water electrolysis are commercial methods for producing hydrogen. For large scale production, the economics generally favor hydrogen from fossil fuels. Since the major part of industrial hydrogen produced today is used in large chemical plants for petroleum refining, ammonia and methanol synthesis, fossil fuels are by far the dominant feedstock. Water electrolysis is more suitable for industry sectors that require very high purity hydrogen, like metallurgy, electronics and pharmaceuticals. Among the 45 million tons of hydrogen produced worldwide annually, approximately $96 \%$ comes from fossil fuel processing (48\% natural gas, $30 \%$ oil, $18 \%$ coal) and only $4 \%$ from water electrolysis [7]. Figure 1 shows the global production of hydrogen.

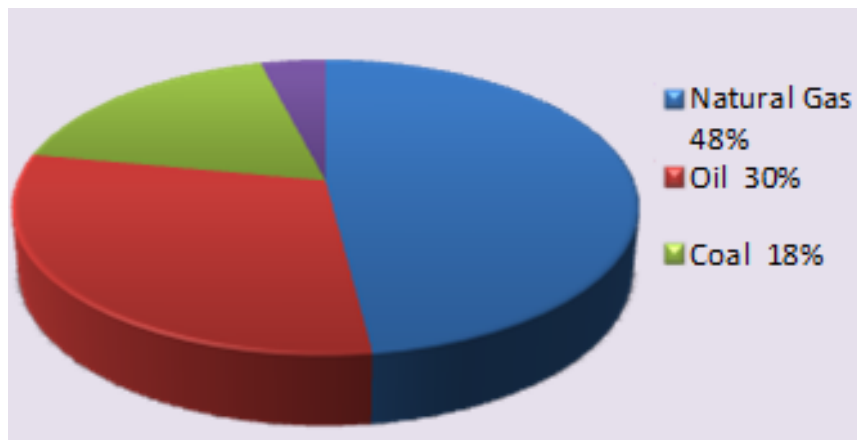

Figure 1: Feedstock used in the current global production of hydrogen [8].

Electrolytic hydrogen production has been scientifically studied for more than a century. According to the literature, hydrogen has been used by for military, industrial and commercial purposes since late $19^{\text {th }}$ century. At the present time, electrolytic hydrogen represents only the $4 \%$ of the global production of the most abundant element of the universe. This is justified considering that electricity expense constitutes the largest fraction of hydrogen production costs [9]. In this review article, we show the recent trend in the hydrogen production scenario, 


\section{International Journal of Science and Research (IJSR) \\ ISSN (Online): 2319-7064}

Index Copernicus Value (2015): 78.96 | Impact Factor (2015): 6.391

highlighting the promising aspects of electrolysis when combined with renewable energy as power source.

\section{Source Hydrogen}

Hydrogen molecule can be generated from different sources, and in numerous methods. These include fossil resources, such as natural gas and coal, as well as renewable resources, such as biomass and water with input from renewable energy sources (e.g., sunlight, wind, waves or hydro-power) [10]. Hydrogen can be produced from any hydrocarbon fuel because by definition these fuels contain hydrogen [11]. However, except for space programs, hydrogen is not being used directly as a fuel or energy carrier, and it is used in refineries to upgrade crude oil (hydro-treating and hydrocracking), in the chemical industry to synthesize various chemical compounds (such as ammonia, methanol, etc.) and in metallurgical processes. Production of hydrogen as energy carrier would require an increase in production rates by orders of magnitude [2]. A variety of process technologies can be used, containing chemical, biological, photolytic, electrolytic and thermo-chemical. Each technology is in a different stage of development, and each offers unique opportunities, benefits and challenges [10].

\subsection{Production of hydrogen from coal and biomass}

Gasification is a process in which coal or biomass is converted into gaseous components by applying heat under pressure and in the presence of air or oxygen and steam. A series of chemical reactions can product a synthesis gas, which is then reacted with steam to create a gas stream with raised hydrogen concentration that can be separated and purified with carbon capture and storage. Alternatively, since growing biomass consumes $\mathrm{CO}_{2}$ from the ztmosphere, producing hydrogen through biomass gasification releases near-zero net greenhouse gases [12,13]. Hydrogen can be produced from coal through a variety of gasification processes (e.g., fixed bed fluidized bed or entrained flow). In practice, high-temperature entrained flow processes are favoured to maximize carbon conversion to gas, thus avoiding the formation of significant amounts of char, tars and phenols. A typical reaction for the process is given in equation (2.1), in which carbon is converted to carbon monoxide and hydrogen. Since this reaction is endothermic, additional heat is required, as with methane reforming. The $\mathrm{CO}$ will be converted to $\mathrm{CO}_{2}$ and $\mathrm{H}_{2}$ through the water-gas shift reaction, shown in equation (2.2).

$$
\begin{aligned}
& \mathrm{C}_{(\mathrm{s})}+\mathrm{H}_{2} \mathrm{O} \stackrel{\text { heat }}{\longrightarrow} \mathrm{CO}+\mathrm{H}_{2} \ldots \ldots . . \\
& \mathrm{CO}+\mathrm{H}_{2} \mathrm{O} \rightarrow \mathrm{CO}_{2}+\mathrm{H}_{2}+\text { heat }
\end{aligned}
$$

On the other hand, hydrogen production from coal is more complex than the production of hydrogen from natural gas. The cost of the resulting hydrogen is also higher. However, since coal is present in numerous parts of the world and will probably be utilized as an energy source regardless, it is worthwhile to explore clean technologies for its application. Like the steam methane reforming process, coal gasification involves three steps. The first step is the treatment of coal feedstock with high temperature steam $\left(1330^{\circ} \mathrm{C}\right)$ to produce syngas, the second a catalytic shift conversion, and third the purification of the hydrogen product [14]. Gasification (i.e., partial oxidation) is one method of production of hydrogen from coal. Coal gasification works by first reacting coal with oxygen and steam under high pressures and temperatures to form synthesis gas, a mixture containing primarily of carbon monoxide and hydrogen. The synthesis gas is cleaned of impurities and the carbon monoxide in the gas mixture is reacted with steam via the water-gas shift reaction to generate additional $\mathrm{H}_{2}$ and $\mathrm{CO}_{2}$. Hydrogen is removed by a separation system and the highly concentrated $\mathrm{CO}_{2}$ stream can subsequently be captured and sequestered. Hydrogen can be used in a combustion turbine or solid oxide fuel cell to produce power, or utilized as a fuel or chemical feedstock [12]. Prior to the development of electricity networks, coal gasification was used to create gas for lighting purposes. The technology is mature but is less-widely used that SMR (steam membrane reforming), despite cheaper fuel costs, because the capital investment costs are higher and more variable and the energy efficiency is lower. Since a greater quantity of $\mathrm{CO}_{2}$ is produced by coal gasification for each unit of produced hydrogen, one might expect a greater efficiency reduction for this technology. On the other hand, membrane technology is expected to reduce the efficiency loss due to $\mathrm{CO}_{2}$ capture [15]. Hydrogen can be produced by decomposing biomass under controlled conditions [10]. Biomass accounts for $15 \%$ of global primary energy consumption and is particularly important in less-developed countries. Technologies to produce hydrogen from biomass are most strongly characterized by their diversity, in terms of both the types of technology and the range of different biomass fuels that are used. All technologies suffer from low yields due of the low hydrogen content of biomass and the $40 \%$ oxygen content which lowers the overall available energy, thus there are no completed industrial-scale demonstrations of any biomass technology for producing hydrogen and cost and efficiency data must be considered speculative. Efficiencies are higher for biomass-derived biofuels (e.g., bioethanol) that are processed prior to the hydrogen production plant; the principle benefit of such fuels would be to decrease the fuel transport costs from the plantation to the hydrogen plant. Biofuel production has increased substantially in recent years, with the loss of land for food production causing controversy [16]. Biomass can also be processed to make renewable liquid fuels, such as ethanol or bio-oil, which are relatively convenient to transport and can be reacted with high-temperature steam to produce hydrogen at or near the point of use. Researchers are also exploring a variation of this technology known as aqueous-phase reforming [12].

\subsection{Production of hydrogen from oil}

Hydrogen can be produced from steam reforming or partial oxidation of fossil oils. Steam reforming, sometimes called fossil fuels reforming, is a method for producing hydrogen or other useful products from hydrocarbon fuels such as natural gas. This is achieved in a processing device called a reformer which reacts steam at high temperature with the fossil fuel. The steam methane reformer is widely used in industry to make hydrogen. There is also interest in the development of much smaller units based on similar technology to produce hydrogen as a feedstock for fuel cells. 


\section{International Journal of Science and Research (IJSR) \\ ISSN (Online): 2319-7064}

Index Copernicus Value (2015): 78.96 | Impact Factor (2015): 6.391

Small-scale steam reforming units to supply fuel cells are currently the subject of research and development, typically involving the reforming of methanol or natural gas but other fuels are also being considered such as propane, gasoline, autogas, diesel fuel, and ethanol [3]. Roughly $98 \%$ available renewable resources for hydrogen production of the current hydrogen generated worldwide is prepared by steam reformation where steam is used to generate hydrogen from methane, typically derived from natural gas. This is the most cost-effective method of hydrogen production. However, natural gas is not a renewable form of fuel and will rise global emissions of carbon dioxide unless a highly efficient method of sequestration is developed. On the contrary, electrolysis uses energy supply to generate oxygen and hydrogen from water [6].

\subsection{Production of hydrogen from gas}

Hydrogen can be produced as a by-product from reforming natural gas or biogas with steam [10]. Natural gas reforming is currently the most efficient, economical and widely used process for production of hydrogen and has been utilized globally for many decades in the oil refinery and fertilizer industries. Steam reforming (SR) is the standard method but membrane reforming has also been demonstrated in smallscale plants [16]. Compact, small-scale reformers, suitable for refueling stations, have been proposed as one option for a hydrogen economy [17]. While this option would remove the requirement for expensive delivery infrastructure in the early stages of a transition to hydrogen, the systems would be too small for CCS to be used so substantial GHG emission savings would be not be achieved. SMR efficiencies are currently in the range 60\%-80\%, with larger plants being more efficient. Efficiencies are expected to rise only slightly in the future but the scale gap should close. Membrane plants are likely to only slightly increase the operating efficiencies [16].

\subsubsection{Production from natural gas}

Hydrogen can currently be produced from natural gas by means of three different chemical processes which are steam methane reforming, partial oxidation and auto thermal reforming. Although several new production concepts have been investigated, none of them is close to commercialization. Steam reforming contains the endothermic conversion of methane and water vapour into hydrogen and carbon monoxide (2.3). The heat is supplied from the combustion of some of the methane feed-gas. The process typically occurs at temperatures of 700 to $850{ }^{\circ} \mathrm{C}$ and pressures of 3 to 25 bar. The product gas contains about $12 \% \mathrm{CO}$, which can be further converted to $\mathrm{CO}_{2}$ and $\mathrm{H}_{2}$ through the water-gas shift reaction (2.2).

$$
\mathrm{CH}_{4}+\mathrm{H}_{2} \mathrm{O} \stackrel{\text { heat }}{\longrightarrow} \mathrm{CO}+3 \mathrm{H}_{2}
$$

Partial oxidation of natural gas is the process whereby hydrogen is produced by the partial combustion of methane with oxygen gas to yield carbon monoxide and hydrogen (2.4). In this reaction, heat is created in an exothermic reaction, and then a more compact design is possible as there is no need for any external heating of the reactor. The $\mathrm{CO}$ produced is further converted to $\mathrm{H}_{2}$ as described in equation (2.2).

$$
\mathrm{CH}_{4}+1 / 2 \mathrm{O}_{2} \rightarrow \mathrm{CO}+2 \mathrm{H}_{2}+\text { heat }
$$

Auto thermal reforming is a combination of both steam reforming (2.1) and partial oxidation (2.3). The total reaction is exothermic, and so it releases heat. The outlet temperature from the reactor is in the range of 950 to $1100{ }^{\circ} \mathrm{C}$, and the gas pressure can be as high as 100 bar. Again, the $\mathrm{CO}$ produced is converted to $\mathrm{H}_{2}$ through the water-gas shift reaction (2.2). The need to purify the output gases adds significantly to plant costs and decrease the total efficiency.

\subsection{Production of hydrogen from algae and alcohols}

Various biological materials can produce hydrogen gas; for example, it can be produced via methods that utilize photosynthesis. The biological hydrogen production with algae is a method of photo biological water splitting which is done in a closed photobioreactor based on the production of hydrogen by algae [18]. Certain microbes, such as green algae and cyan bacteria, produce hydrogen by splitting water in the presence of sunlight as a byproduct of their natural metabolic processes. Other microbes can extract hydrogen directly from biomass. Algae produce hydrogen under certain conditions. In 2000 it was discovered that if Chlamyldomonas C. reinhardtii algae are deprived of sulfur, they will switch from the production of oxygen, as in normal photosynthesis, to the production of hydrogen. Recent work has shown that lack of sulfur from the growth medium of this species causes a specific but reversible decline in the rate of oxygenic photosynthesis [18]. However, it does not affect the rate of mitochondrial respiration [19]. Under such conditions, it was possible to photo produce and accumulate significant volumes of $\mathrm{H}_{2}$ gas using the green alga $C$. reinhardtii, in a sustainable process that could be employed continuously for several days. Thus, progress was achieved by circumventing the sensitivity of the Fe hydrogenase to $\mathrm{O}_{2}$ through a temporal separation of the reactions of $\mathrm{O}_{2}$ and $\mathrm{H}_{2}$ photo production, i.e. by the so-called "two-stage photosynthesis and $\mathrm{H}_{2}$ production" process [19].

Recent advancements in fuel cell technology have spurred an interest in converting alcohols into hydrogen rich gas streams, on a small scale and up to industrial scale. Such technology enables one to convert a non-toxic liquid to hydrogen to feed fuel cells. There is also an interest in converting alcohol/water mixtures, for example ethanol and water, such as sugar from biomass fermentation, directly into electricity [20]. Catalytic steam reforming of alcohols is a well-known process for producing a hydrogen rich gas stream. This is particularly useful for providing energy to fuel cells. Reforming is highly endothermic, therefore requiring significant energy input, by using a portion of the fuel to be converted, to drive the reaction forward. Reforming also requires a relatively long catalyst contact times, on the order of seconds, which requires significant equipment investment [20].

\section{Volume 6 Issue 7, July 2017 www.ijsr.net}




\section{International Journal of Science and Research (IJSR) \\ ISSN (Online): 2319-7064}

Index Copernicus Value (2015): 78.96 | Impact Factor (2015): 6.391

\subsection{Production of hydrogen from water electrolysis}

Hydrogen can be produced from water electrolysis several power sources, renewable or not. The latter are also referred as fossil fuels [5]. Numerous technologies are already presented in the marketplace for the industrial hydrogen production. The first commercial technology was in 1920s, where the pure hydrogen was produce from electrolysis of water. After that, in the 1960s, the industrial production of hydrogen moved towards a fossil-based feedstock, which now is consider as the main source for hydrogen production [5]. Electrolysis uses an electric current to split water into hydrogen and oxygen. The electricity required can be generated using any of number of resources. However, to minimize greenhouse gas emissions, electricity generation using renewable energy technologies, such as wind, solar, geothermal, and hydroelectric power, nuclear energy, or coal and natural gas with carbon sequestration are preferred [3]. Heat from a nuclear reactor can be used to improve the efficiency of water electrolysis to produce hydrogen. By increasing the temperature of water, less electricity is required to split it into hydrogen and oxygen, which reduces the total energy required [3]. Another water-splitting method uses high temperatures generated by solar concentrators (mirrors that focus and intensify sunlight) or nuclear reactors to drive a series of chemical reactions to split water into hydrogen and oxygen. All of the intermediate process chemicals are recycled within the process. Hydrogen provides the connecting point between renewable electricity production and transportation, stationary and portable energy needs. When the electricity from solar photovoltaics, wind, geothermal, ocean and hydro technologies is used to produce and store hydrogen, the renewable source becomes more valuable and can meet a variety of needs. In transportation applications, hydrogen provides a way to convert renewable resources to fuel for vehicles. Renewably produced hydrogen for transportation fuel is one of the most popular hydrogen economy goals, as it can be domestically produced and emissions-free [14].

\subsection{Hydrogen from splitting of water}

Hydrogen can be produced from the splitting of water through various processes. This section briefly discusses water electrolysis, photo-electrolysis, photo-biological production and high-temperature water decomposition.

\subsubsection{Water electrolysis}

Water electrolysis is the process where water is split into hydrogen and oxygen through the application of electrical energy, as in equation (2.5). The total energy that is needed for water electrolysis is increasing slightly with temperature, while the required electrical energy decreases. A hightemperature electrolysis process might, therefore, be preferable when high-temperature heat is available as waste heat from other processes. This is especially important globally, as most of the electricity produced is based on fossil energy sources with relatively low efficiencies [21].

$$
\mathrm{H}_{2} \mathrm{O}+\text { electricity } \rightarrow 1 / 2 \mathrm{O}_{2}+\mathrm{H}_{2}
$$

\subsubsection{Alkaline electrolysis}

Alkaline electrolyzes use an aqueous $\mathrm{KOH}$ solution (caustic) as an electrolyte that usually circulates through the electrolytic cells. Alkaline electrolysers are suitable for stationary applications and are available at operating pressures up to 25 bar. Alkaline electrolysis is a mature technology, with a significant operating record in industrial applications that allows remote operation [22,23]. The following reactions take place inside the alkaline electrolysis cell as in following equations:

$$
\begin{aligned}
& \text { Electrolyte: } \quad 4 \mathrm{H}_{2} \mathrm{O} \rightarrow 4 \mathrm{H}^{+}+\mathrm{OH}^{-} \ldots \text { (2.6) } \\
& \text { Cathode: } \quad 4 \mathrm{H}^{+}+4 e^{-}+2 \mathrm{H}_{2}
\end{aligned} \begin{aligned}
& \ldots \text { (2.7) } \\
& \text { Anode: } 4 \mathrm{OH}+\mathrm{O}_{2} \rightarrow 2 \mathrm{H}_{2} \mathrm{O}+4 e^{-} \text {.(2.8) } \\
& \text { Sum: } \quad 2 \mathrm{H}_{2} \mathrm{O} \rightarrow 2 \mathrm{H}_{2}+\mathrm{O}_{2}
\end{aligned}
$$

Commercial electrolysers usually consist of a number of electrolytic cells arranged in a cell stack. The major R\&D challenge for the future is to design and manufacture electrolyser equipment at lower costs with higher energy efficiency and larger turn-down ratios.

\subsubsection{Polymer electrolyte membrane (PEM) electrolysis}

The principle of PEM electrolysis is presented in equations (2.10) and (2.11). PEM electrolysers require no liquid electrolyte, which simplifies the design significantly. The electrolyte is an acidic polymer membrane. PEM electrolysers can potentially be designed for operating pressures up to several hundred bar, and are suited for both stationary and mobile applications. The disadvantage of this technology is the limited lifetime of the polymer electrolyte $[22,23]$. The main benefits of PEM over alkaline electrolysers are the higher turndown ratio, the increased safety because of the absence of $\mathrm{KOH}$ electrolytes, a more compact design due to higher densities, and higher operating pressures. Water in the PEM electrolyzer is fed to the anode, where it is split into a hydrogen cation and oxygen. The hydrogen cations pass through the polymer membrane to the cathode. At the cathode, the hydrogen cations merge with the electrons flowing from the outer circuit, which results in the creation of gas hydrogen. The efficiency of a PEM electrolyzer is around 55-70\% [23].

$$
\begin{aligned}
& \text { Anode: } 4 \mathrm{H}_{2} \mathrm{O} \rightarrow \mathrm{O}_{2}+2 \mathrm{H}^{+}+2 e^{-} \ldots \\
& \text { Cathode: } 2 \mathrm{H}^{+}+2 e^{-}+\mathrm{H}_{2} \quad \ldots \ldots \ldots .
\end{aligned}
$$

With relatively high cost, low capacity, poor efficiency and short lifetimes, the PEM electrolysers currently available are not as mature as alkaline electrolysers. It is estimated that the performance of PEM electrolysers can be improved considerably by additional work in materials development and cell stack design.

\subsubsection{High-temperature electrolysis}

Nowadays, hydrogen production is primarily based on fossil fuels and most specifically on natural gas [24]. Hightemperature electrolysis is based on technology from hightemperature fuel cells. The electrical energy required to dissociate water at $100{ }^{\circ} \mathrm{C}$ is higher than electrolysis 1000 ${ }^{\circ} \mathrm{C}$. This means that a high-temperature electrolyser may operate at higher process efficiencies than low-temperature 


\section{International Journal of Science and Research (IJSR) \\ ISSN (Online): 2319-7064}

Index Copernicus Value (2015): 78.96 | Impact Factor (2015): 6.391

electrolysers. Solid oxide electrolyser cell (SOEC) is considered as a typical technology. This electrolyser is based on the solid oxide fuel cell, which usually runs between 700 and $1000{ }^{\circ} \mathrm{C}$. Similar to the main challenges for SOFCs, the main R\&D needs for SOECs relate to materials development and thermo-mechanical stress within the functional ceramic materials [25].

\subsubsection{Photo-biological production (biophotolysis)}

Hydrogen may also be produced from biological processes involving organic compounds. Photobiological production of hydrogen is based on two steps: photosynthesis (2.12) and hydrogen production catalysed by hydrogenases (2.13) in, for example, green algae and cyanobacteria. Long term basic and applied research is needed in this area, but if successful, a long-term solution for renewable hydrogen production will result. It is of vital importance to understand the natural processes and the genetic regulations of $\mathrm{H}_{2}$ production. Metabolic and genetic engineering may be used to demonstrate the process in larger bioreactors. Another option is to reproduce the two steps using artificial photosynthesis [26].

$$
\begin{gathered}
\text { Photosynthesis: } 4 \mathrm{H}_{2} \mathrm{O} \rightarrow 4 \mathrm{H}^{+}+\mathrm{O}_{2}+4 e^{-}(2.12) \\
\text { Hydrogen Production: } 4 \mathrm{H}^{+}+4 e^{-}+2 \mathrm{H}_{2}
\end{gathered}
$$

The most effective photobiological systems for $\mathrm{H}_{2}, \mathrm{O}_{2}$ production are those based on microalgae, like green algae and cyanobacteria. Efficiencies under ideal conditions approach about $10 \%$, but a big difficulty arises from the fact that the algal systems is saturated at solar irradiances over 0.03 suns [22,23,227]. Generally, photosynthetic systems do not rise $\mathrm{H}_{2}$, but rather reduce $\mathrm{CO}_{2}$ to carbohydrates. However, it is possible to modify the conditions if the decreasing end of the photosynthetic process is coupled to a hydrogen evolving enzyme, as hydrogenase or nitrogenase.

\subsubsection{High-temperature decomposition}

High-temperature splitting of water occurs at about $3000{ }^{\circ} \mathrm{C}$. At this temperature, $10 \%$ of the water is decomposed and the remaining $90 \%$ can be recycled [28]. To decrease the temperature, other processes for high temperature splitting of water have been suggested that thermo-chemical cycles, hybrid systems coupling thermal and electrolytic decomposition, direct catalytic decomposition of water with separation via a ceramic membrane (thermo-physic cycle) and plasma-chemical decomposition of water in a doublestage $\mathrm{CO}_{2}$ cycle. For these processes, efficiencies above $50 \%$ can be expected and could possibly lead to a major decrease of hydrogen production costs. The main technical issues for these high-temperature processes relate to materials development for corrosion resistance at high temperatures, high-temperature membrane and separation processes, heat exchangers, and heat storage media. Design aspects and safety are also important for high-temperature processes $[29,30]$.

\subsubsection{Thermo-chemical water splitting}

Thermo-chemical water splitting is the conversion of water into hydrogen and oxygen by a series of thermally driven chemical reactions. Thermo-chemical water-splitting cycles have been known since 1970s [31]. An example of a thermo- chemical process is the iodine/sulphur cycle, outlined in equations (3.14), (3.15) and (3.16). For this reaction, the development needs are to capture the thermally split $\mathrm{H}_{2}$, to avoid side reactions and to eliminate the use of noxious substances. The corrosion problems associated with the handling of such materials are likely to be extremely serious $[32,33]$. The SI cycle generates hydrogen in following three steps chemical reactions:

$$
\begin{array}{ll}
\left(850{ }^{\circ} \mathrm{C}\right): & \mathrm{H}_{2} \mathrm{SO}_{4} \rightarrow \mathrm{H}_{2} \mathrm{O}+\mathrm{SO}_{2}+1 / 2 \mathrm{O}_{2} \ldots(2.14) \\
\left(120^{\circ} \mathrm{C}\right): & \mathrm{I}_{2}+\mathrm{SO}_{2}+2 \mathrm{H}_{2} \mathrm{O} \rightarrow \mathrm{H}_{2} \mathrm{SO}_{4}+2 \mathrm{HI}(2.15) \\
\left(450^{\circ} \mathrm{C}\right) & \mathrm{HI} \rightarrow \mathrm{I}_{2}+\mathrm{H}_{2}
\end{array}
$$

\subsubsection{Photoelectrochemical water splitting}

The cleanest way to produce hydrogen is by using sunlight to directly split water into hydrogen and oxygen. Photoelectrochemical (PEC) systems combine both photovoltaics and electrolysis into a one-step water splitting process. These systems use a semiconductor electrode exposed to sunlight in combination with a metallic or semiconductor electrode to form a PEC cell. Multi junction cell technology established by the photovoltaic industry is utilized for photoelectrochemical (PEC) light harvesting systems that generate sufficient voltage to split water and are stable in a water/electrolyte environment. The NRELdeveloped PEC system generates hydrogen from sunlight without the expense and complication of electrolyzers, at a solar-to-hydrogen conversion efficiency of $12.4 \%$ lower heating value using captured light. Research is underway to identify more efficient, lower cost materials and systems that are durable and stable against corrosion in an aqueous environment [34-36].

\subsection{Wind-electrolysis}

Over the last years, wind power has developed itself as an economic grid-connected electricity generating technology, but its use in stand-alone power systems has been limited, because of the lack of suitable for energy storage. Hydrogen produced via water electrolysis could be such storage medium in the near future, especially in isolated remote areas, where the cost of electricity is high. Nevertheless, a number of demonstrations of wind electrolysis units have already been installed [37].

\subsection{Geothermal energy electrolysis}

Geothermal energy is a clean domestic energy source that is available 24 hours a day. The average geothermal power plant produces electricity $90 \%$ of the time, compared with $65-75 \%$ for coal and nuclear-powered plants [14]. Geothermal energy can be used like thermal energy source to supply heat for high temperature electrolysis and thus substitute a part of the electricity needed. Jonsson et al. in 1992 conducted a feasibility study exploring the use of geothermal energy in hydrogen production. Geothermal fluid was utilized to heat fresh water up to $200{ }^{\circ} \mathrm{C}$, generating steam. The steam is further heated to $900{ }^{\circ} \mathrm{C}$ by utilizing heat produced within the electrolysis unit. The electrical power of this conventional process was reduced from $4.6 \mathrm{kWh} / \mathrm{Nm}^{3}$ to $3.2 \mathrm{kWh} / \mathrm{Nm}^{3}$ of $\mathrm{H}_{2}$ for the HOT ELLY process implying electrical energy production of

\section{Volume 6 Issue 7, July 2017 www.ijsr.net}




\section{International Journal of Science and Research (IJSR) \\ ISSN (Online): 2319-7064}

Index Copernicus Value (2015): 78.96 | Impact Factor (2015): 6.391

29.5\%. The geothermal energy needed in the process of hydrogen production through high temperature electrolysis was estimated to be about $0.5 \mathrm{kWh} / \mathrm{Nm}^{3} \mathrm{H}_{2}$. This way a substantial decreasing of production cost of hydrogen could be accomplished. According to this study, using high temperature electrolysis supplied with geothermal steam at $200{ }^{\circ} \mathrm{C}$, would result in a reduction of the production cost by around $19 \%$. However, geothermal energy will not replace fossil fuels as the major energy sourcetub it can be used as a thermal energy source to supply heat for high temperature electrolysis and thereby substitute a part of the electricity needed [37].

\subsection{Photoelectrolysis}

Photoelectrolysis is one of the renewable methods of production of hydrogen, exhibiting promising efficiency and costs $[22,23,25,27,38]$. The photoelectrolysis system can be classified to four categories photochemical systems, semiconductor systems, photobiological systems and hybrid systems [22]. The light absorption of the semiconductor material is directly proportional to the photoelectrode efficiency. Semiconductors that have wide bands can offer the necessary potential for cracking water [39]. Fujishima and Honda in 1972 were the first to report the generation of hydrogen and oxygen in a photoelectrochemical cell utilizing a $\mathrm{TiO}_{2}$ electrode illuminated with near ultraviolet light. In photoelectrochemical cells, a light-absorbing semiconductor is utilized as either the anode or the cathode in an electrochemical cell. In this kind of cell a single crystal of $\mathrm{TiO}_{2}$ was used as the photoanode and electrons released from the anode were directed through a wire to a $\mathrm{Pt}$ electrode, at which hydrogen evolved [40]. The reaction based on the type of semiconductor material and on the solar intensity, which produces a current density of 10-30 $\mathrm{mA} / \mathrm{cm}^{2}$. At these current densities, the voltage necessary for electrolysis is approximately $1.35 \mathrm{~V}$ [22]. Each layer of semiconductor and catalytic photovoltaic influences on the overall performance of the photoelectrochemical system. Some experiments have been conducted on numerous materials, such as $\mathrm{TiO}_{2}, \mathrm{Fe}_{2} \mathrm{O}_{3}, \mathrm{WO}_{3}, \mathrm{n}-\mathrm{GaAs}, \mathrm{n}-\mathrm{GaN}$ for a photoanode, and CIGS/Pt (Cu-In-Ga-diselenid), p-InP/Pt an $\mathrm{p}-\mathrm{SiC} / \mathrm{Pt}$ for a photocathode $[22,23,27]$. Rossi et al. in 2011was produced hydrogen production by water photoelectrolysis. In this report, $\mathrm{TiO}_{2}$ and cyanin chloride $\left(\mathrm{C}_{27} \mathrm{H}_{3} 1 \mathrm{ClO}_{16}\right.$ an organic dye $)$ was used as semiconductor and sensibilizer, respectively. $\mathrm{TiO}_{2}$ was deposited on cathode electrode, the effect of the sensibilizer on cathode electrode and spectrophotometric technique was used to evaluate water absorption properties. The experimental investigation was concentrated on the selected sensibilizer performances. It found that the hydrogen production increase with respect to a no sensibilizer use. A $11.2 \%$ maximum solar-tohydrogen photolytic conversion efficiency was found when the proposed arrangements are applied to a basic watery solution. The experimental results exhibited good improvement on hydrogen production after using sensibilizer and semiconductor [33].

\section{Factors affecting hydrogen production in electrolysis process}

\subsection{Effect of electrolyte concentration}

Producing hydrogen from seawater is indirect electrolysis of seawater that is to desalinate seawater before using the water for the electrolysis process, which would be able to eliminate chlorine gas production during the electrolysis process. However, this method requires additional capital cost to operate, as it would need a desalination process prior to the electrolysis process [41]. Bases and acids are used to change the non conductive nature of pure water to conductive water. These chemicals have a great reducing effect on the potential value of an electrolyzer, because they improve the ionic conductivity of aqueous electrolyte compounds. On the other hand, the concentration level of acidic and alkali solutions are limited in practice due to the highly corrosive behavior of these solutions [42]. A 25\% to $30 \% \mathrm{KOH}$ aqueous solution is reported to have a wide use in electrolyzers [9]. It resulted that a greater hydrogen volume is generated in the same amount of time with a higher alkali concentration. This could be due to high rate of reaction and $\mathrm{NaOH}$ has a tendency to speed up the reaction more effectively than $\mathrm{KOH}$. This is attributed to the fact that ionic radius of sodium is small than potassium [43] The advantage of indirect electrolysis of seawater is to be able to use the readily developed technology of fresh water electrolysis, and hence, no chlorine produced at the anode of the cell during the electrolysis process [41]. Mahrous and et al. in 2011 observed that the rate of hydrogen production was increased by increasing in concentration of $\mathrm{KOH}$ in solution. This is due to the increase in the electrical conductivity. Increasing in the ionic conductivity causes an increase in the electrical current passing through the solution and, as a result, to an increase in hydrogen production for all tested models [44]. Jabar and Ibrahim explained that the rate of hydrogen produced using $\mathrm{NaHCO}_{3}$ was higher than $\mathrm{NaOH}$. They founded that the weight loss of electrodes in the samples of $\mathrm{NaHCO}_{3}$ and $\mathrm{NaOH}$ is approximately similar to the weight loss of electrodes in the water sample under the same condition [45]. Abdel-Aal et al. in 2010 showed the influence of changing the $\mathrm{Cl}^{-}$concentration in sea water on the ratio of hydrogen to total chlorine. The experiments took place under the settings of: $6-20 \mathrm{~V}, 25-126 \mathrm{~mA} / \mathrm{cm}^{2}$ and up to $1000 \mathrm{C}$. At concentrations lower than $600 \mathrm{mmol} / \mathrm{L}$, there was a sharp decrease with increase in the chloride level, while at concentrations greater than $600 \mathrm{mmol} / \mathrm{L}$, the effect was insignificant since these concentrations are high enough to avail $\mathrm{Cl}^{-}$ions at the anode [41]. One of the earliest studies on the direct electrolysis of seawater has shown that hydrogen is evolved at high current efficiency at the cathode of the electrolysis cell, while chlorine is produced in the form of sodium hypochiorite $(\mathrm{NaOCl})$ in large quantities at the anode [46].

\subsection{Effect of $\mathrm{pH}$}

Abdullah et al. in 2013 described the influence of $\mathrm{pH}$ on the hydrogen and oxygen production. The experiment was run out that within the range of $\mathrm{pH}$ from 3 to 13 . It concluded that alkaline region provided better production[47]. Jabar and Ibrahim in 2013 studied the effect of electrode material 


\section{International Journal of Science and Research (IJSR) \\ ISSN (Online): 2319-7064}

Index Copernicus Value (2015): 78.96 | Impact Factor (2015): 6.391

on hydrogen production. The stainless steel electrodes exhibited pronounced using weight loss method hydrogen producing rate and also $\mathrm{pH}$ changes of the different concentration at all samples. The analysis of variance suggests that types of electrode materials and $\mathrm{pH}$, as well as their interactions, have significant effects on the production rate. The different $\mathrm{pH}$ level can cause different type of gas to be produced. On the other hand, the weight loss of stainless steel, gas production and the $\mathrm{pH}$ value at $0.4 \mathrm{M}$ of sodium bicarbonate and sodium hydroxide are good production [45].

\subsection{Effect of temperature}

Temperature is known to be one of the most effective factors on the electric power demand of an electrolytic cell. General, hydrogen production is increased as temperature increase [9]. The reasons for this behavior can be drawn from the thermodynamic characteristics of a water molecule since its splitting reaction potential is known to decrease as the temperature increases. Additionally, surface reaction and electrical conductivity of an electrolyte increase with temperature [42]. Traditional room-temperature electrolysis is less effective economically than electrolysis high temperature due to some of the energy is supplied as heat, which is cheaper than electricity, and because the electrolysis reaction is more efficient at higher temperatures (Abdel-Ala and et.al 2010). The operation of a test hydrogen production plant for two years had been measured by Bailleux in 1981. In this study, alkaline solution potassium hydroxide $(40 \% \mathrm{wt})$ as an electrolyte was decomposed under the pressure, current density and temperature range conditions of 20 bar, $10 \mathrm{kA} \mathrm{m}^{-2}$ and $120{ }^{\circ} \mathrm{C}$ to $160{ }^{\circ} \mathrm{C}$, respectively. On the other hand, some stability problems like container cracks and gasket leaks was noted due the increasing of temperature and pressure. In more recent investigation, high temperature electrolysis is referred to cases with much higher temperature ranges.

As an example of high temperature range, Mingyi et al. in 2008 studied electrochemical and thermodynamic characteristics of a high temperature steam electrolyzer (HTSE). In this study, In this work, the total electrolysis efficiency contained three factors which are electrical, thermal and electrolysis efficiency, the value of the total efficiency was 70, 22 and 8\%, respectively. Regarding their result, increased cell temperature caused a higher thermal and lower electrical efficiency values where the electrolysis efficiency remained without any significant changes. The researchers also described the possibility of coupling the HTSE device with a high temperature gas cooled reactor (HTGR). An overall efficiency of the electrolytes of 59\% was verified and was remarkably higher than the $33 \%$ initial value when temperature of electrolyte reached to $1000^{\circ} \mathrm{C}$. The process efficiency was listed to be more than twice of those of the low temperature electrolyzes of the time. Ganley in 2009 also studied the efficiency of electrolyte solution at high temperature. The tests were run out in a chemical resistant container since the highly concentrated potassium hydroxide electrolyte was heated up to $400{ }^{\circ} \mathrm{C}$. During the study, the electrolyte was subjected to different values of compression during the experimental work. The electrolyte concentration was set at $19 \mathrm{M}$ at the starting phase of each experiment, which is highly corrosive to many metals and alloys. Lower voltage level was required to reach any given current density for temperatures between $200{ }^{\circ} \mathrm{C}$ and 400 ${ }^{\circ} \mathrm{C}$. The results showed that a potential level of $1.8 \mathrm{~V}$ was sufficient to cause a current density of $200 \mathrm{~mA} \mathrm{~cm}^{-2}$ at 200 ${ }^{\circ} \mathrm{C}$. Under the same pressure and current density, this value was only $1.5 \mathrm{~V}$ when the electrolyte was heated up to $400{ }^{\circ} \mathrm{C}$ [48]. As shown by Nagai et al. 2003, described equilibrium voltage which is heat can reduce the potential of water. This parameter also enlarges the size of the gas bubbles and decreases their increasing velocity. The latter-mentioned causes a larger void fraction in the electrolyte and decreases the efficiency as a result [49].

\subsection{Effect of pressure}

Appleby et al. 1978 tried to lower the cost of production of hydrogen by introducing higher current density conditions in electrolyzers. Regarding to this work, high pressure electrolytes lead to consume less energy in the process of electrolysis. The reason behind that is the reduction influence of pressure on the gas bubbles, which lead to the Ohmic potential fall and power dissipation to decrease. Moreover, high pressure electrolysis has less power demand for the phase of product compression [50]. The experiments were tested in a typical three compartment electrolyzer with operating temperature between $25^{\circ} \mathrm{C}$ and $90{ }^{\circ} \mathrm{C} 1 \mathrm{~mA} \mathrm{~cm}$ and by using the plates of $\operatorname{Pt}(99.99 \%)$ and Nickel. The electrolyte of a $34 \%$ wt or $25 \%$ wt $\mathrm{KOH}$ solution was used as electrolyzer. It demonstrated that an overall potential drop to $100 \mathrm{mV}$ when the experiment was evaluated at 30 atm. No significant further potential fall of was recorded at higher voltage values (up to $40 \mathrm{~atm}$ ). A cording to to a similar work in 1980 for LeRoy, the researchers calculated that the energy consumption of compressing a liquid electrolyte to be much less than those of gas state hydrogen compression. Those calculations were based on the results of previous work of LeRoy et al. 1980. The perfect condition of temperature and pressure for electrolytic hydrogen production to be around $70 \mathrm{MPa}$ and $250{ }^{\circ} \mathrm{C}$. High temperature and intense pressure will effect on Gibbs energy and enthalpy levels of an electrolysis process. Therefore, lower voltage will be required as the temperature rises in high pressures and vice versa. On the contrary, they found the voltage rise to be negligible when voltage levels higher than 20MPa. This behavior became more sensible at lower temperatures. Finally, an electrolysis efficiency improvement of 5\% was recorded. Another 50\% of energy was saved at the compression phase of high pressure electrolytic hydrogen production.

\subsection{Electrical resistance of the electrolyte}

Electrical resistance of an object is an evaluation of its opposition to the passage of electric current. The level of this force is proportional to the cross section area and the length of the current path and the material resistivity of the conducting material. The relationship between these variables is displayed in following equation 2.17 as bellow.

$$
R=\frac{\rho L}{A}
$$

\section{Volume 6 Issue 7, July 2017 www.ijsr.net}




\section{International Journal of Science and Research (IJSR) \\ ISSN (Online): 2319-7064}

Index Copernicus Value (2015): 78.96 | Impact Factor (2015): 6.391

Where $A$ is the cross section area, $\rho$ is the material resistivity, $R$ is the electrical resistance, and $l$ is the length of the current path. Inside the cell, electrons mobile from the surface of an electrode, move through the electrolyte and end their journey at the surface of the other electrode. It could be assumed the path as an object with the same length as the distance between electrodes, the cross section of the area of electrodes overlap and an equivalent resistivity value. The equivalent resistivity contains of different variables such as the electrodes resistivity, electrical admittance of the electrolyte and the reaction between electrodes surfaces and electrolyte. Hence, the equivalent resistivity is a function of the following variables [9].

\subsection{Effect of electrical conductivity}

By reducing the distance between electrodes, lower electrical resistance can be obtained. It can be concluded that positioning the electrodes too close to each other will decrease the process efficiency [9]. Hegazy in 2005, using nafion 117 a membrane is preferable as it is considered a good separator between hydrogen and oxygen gases it prevents the formation of side reaction because it allows only water and the proton to pass [2]. Lipovestsky and et al. in 2004 offered a new method for producing gaseous hydrogen which is called a water dissociation method. It is based on the process of electrolytic dissociation of water with subsequent reduction of the hydrogen ions by means of the electrons which are released during disintegration of hydroxyl ions in the plus electric field created by the hydrogen ions. The external process electric circuit is absent in the technique of water dissociation, and this decreases significantly the electric energy consumption rate as compared with water electrolysis, meanwhile a number of process advantages is achieved as abandonment of the electrolyte. All this offers for production of hydrogen whose cost should be less than the cost of petroleum-based fuel. Along with hydrogen production the method ensures the generation of electric and thermal energy [51].

Mahrous and et al in 2011 described the effects water electrolysis unit is highly affected by the voltage input and the gap between the electrodes. Higher rates of produced hydrogen can be gained at smaller space between the electrodes and also at higher voltage input. Higher efficiency of system was also obtained at smaller gap distances between the pair of electrodes [44]. Less resistive current path is known to be a result of using electrodes with larger surface areas. A series of experiments have been conducted in order to test the effects of using electrodes of different sizes on the process efficiency [9].The first technique of producing hydrogen from seawater is indirect electrolysis of seawater that is to desalinate seawater before using the water for the electrolysis process, which would be able to eliminate chlorine gas production during the electrolysis process. However, this method requires additional capital cost to operate, as it would need a desalination process prior to the electrolysis process [41]. A two phase flow model of alkaline water electrolysis was established, succeeding in explaining the influences of bubbles between electrodes on efficiency of alkaline water electrolysis, especially the existence of optimum condition and water electrolysis limit. For estimation of the model, optimum condition, bubble rising velocity, bubble diameter and local current density profile were measured, showing the sound validity of the model [49]. Roy and et al. in 2011 reported the results for the $\mathrm{pH}$ of buffer solutions free of chloride ion and with ion chloride. The remaining six buffer solutions have saline media of the ionic strength $\mathrm{I}=0.16 \mathrm{~mol} \mathrm{~kg}{ }^{-1}$, matching closely to that of the physiological sample. Conventional $\mathrm{pH}$ values for the three buffer solutions without the chloride ion and six buffer solutions with the chloride ion at $\mathrm{I}=0.16 \mathrm{~mol}$ $\mathrm{kg}^{-1}$ from $5^{\circ} \mathrm{C}$ to $55^{\circ} \mathrm{C}$ have been calculated. Five of these buffers phosphate standard are recommended as standards for the physiological $\mathrm{pH}$ range 7.5 to 8.5 [52].

\subsection{Electrode Material}

A wide range of materials are being used as electrodes. The properties of electrode materials are electrical resistance, electrical resistance and corrosion resistivity. Platinum and gold are considered to be two of the best metal for being used as electrodes. However, high prices limit their usage in industrial and commercial electrolyzers. Aluminum, Nickel, Raney nickel and cobalt are the most common electrode materials for alkaline electrolytic. This popularity is the result of their satisfactory price range, corrosion resistance and chemical stability [9, 53]. Appleby et al. 1978 conducted a set of experiments by using different electrodes such as 99.99\% pure Ni, Pt, Ir and Rh as well as Ni cloth, Ni sinter, $\mathrm{Ni}-\mathrm{Cd}$ and low impregnation Nickel and cobalt molybdate catalyst on nickel sinter. Each electrode was pre-anodized in order to obtain stable potential characteristics. The experimental express nickel to exhibit more desirable potential characteristics among the other materials. Moreover, their result found that porous sintered electrodes to be 30 times more active those with a smooth surface. However, platinum electrodes show higher activity levels in contact with $\mathrm{KOH}$ aqueous solutions in comparison with molybdenum plates. Souza et al. 2008 showed utilization of 1-butyl-3-methylimidazole tetrafluoroborate $\left({\left.\mathrm{BMI}-\mathrm{BF}_{4}\right)}\right.$ ionic liquid will lead to exceptional efficiency levels for almost all electrode plate [54].

\subsection{Separator material}

Placing a separator plate in a cell, blocks the free movement of mass and ions to some extent. Furthermore, the existing of such barrier increases the void fracture by further gathering of gas bubbles in the electrolyte [49]. In addition, the effective electrical resistance of a separator plate is frequently calculated to be as large as three to five times of those of the electrolyte solutions [35]. Electrical resistance of a separator depends on different factors as corrosion, temperature and pressure [55]. Back in middle 1990's many scientists named asbestos to be the best choice for being used as a diaphragm due to its highly wettable and porous structure. These features reason a plate to display electrical resistance in practice [56]. However, asbestos is known to be a toxic and hazardous material[55]. These characteristics caused the researchers to start looking for substitute materials. Currently there are different materials and technologies available to decrease the negative electrical effect of separators [57].

\section{Volume 6 Issue 7, July 2017 www.ijsr.net}




\section{International Journal of Science and Research (IJSR) \\ ISSN (Online): 2319-7064}

Index Copernicus Value (2015): 78.96 | Impact Factor (2015): 6.391

\subsection{Effect of Applied Voltage and Current}

Yuvaraj and Santhanaraj studied that the effect of applied voltage on the hydrogen evolution reaction (HER) of cylindrical graphite electrode for potassium hydroxide $(0.025 \mathrm{M})$ at $593 \mathrm{~K}$. The applied voltage was varied from 4.5 to $12 \mathrm{~V}$. The result experiment showed that the rate of production of hydrogen gas gradually increases with rise in applied voltage. The plausible reason is the uniform charge density increases on the surface of cylindrical electrode [42]. The graphite electrode in an electrolyte of $5 \mathrm{~mol}$ of $\mathrm{NaOH}$ per liter was used by Senftle et al. in 2010. It was noted that a during AC electrolysis, little or no gas was formed via current through the cell. If the electrodes are of a different area at a relatively low potential, $\mathrm{H}_{2}$ and $\mathrm{O}_{2}$ gases are formed on the small-area electrode only, while at a higher potential, $\mathrm{H}_{2}$ and $\mathrm{O}_{2}$ gases are formed at both electrodes [58]. The over potential on the cathode is directly related to the formation of hydrogen in the vicinity of the electrode. Physical properties as surface roughness will enhance electron transfer by depolarization of the bubbles and adding reaction area, which in turn increase the rate of electrolysis [59]. The objective of Ranganathan's work in 2007 was to conduct water electrolysis at room temperature with reduced energy costs for hydrogen production. The amount of hydrogen produced per $\mathrm{W}$-hr was found to be higher at lower voltages $\left(\mathrm{E}_{0} \sim 0.2 \mathrm{~V}\right)$. However, since the time taken to produce hydrogen is longer, operating at $\mathrm{E}_{0} \sim 0.5 \mathrm{~V}$ was found to be more practical. The current through the circuit bears an almost linear relationship with hydrogen produced per minute [60]. Kotharia and et al. in 2006 conducted experimental about effect of input voltage to the electrodes on hydrogen production rate (HPR) and efficiency $(\eta)$ of hydrogen production was studied. The input DC potential to the cell was maintained at 1.4, 1.6, 1.8, 2.0, 2.2 , 2.4, 3.0, 6.0, 9.0 and $12.0 \mathrm{~V}$. The best efficiency was found at optimum input potential between 2.0 and $2.4 \mathrm{~V}$. The extra-over potential voltage to the electrodes would be the cause of energy loss through heat [61].

\subsection{Effect of Time}

The hydrogen production was extended to maximum of 800 $\mathrm{cm}^{3} /$ min and thus reduced to reach the stable state. The unchanged of hydrogen production for the period of $90 \mathrm{~min}$ shows that the electrode remains stable state without any damage on the electrode surface during the testing time. After $90 \mathrm{~min}$, the graphite electrode is regenerated by drying in flow of air at $50{ }^{\circ} \mathrm{C}$ for $5 \mathrm{~h}$ and the experiment is conducted under same conditions. The rate of production of hydrogen is much more similar to that of initial run [42]. Hegazy 2005 was studied the effect of anode electrode and current efficiency on $\mathrm{O}_{2}$ production. The parameters of process were electrolyte type, the electrolyte concentration, cathode type, the time of electrolysis and current value, explains the effect of using different anode materials such as platinum and graphite electrode on the efficiency of $\mathrm{O}_{2}$ $\left(10 \% \mathrm{KOH}, \mathrm{t}=90 \mathrm{~min}, \mathrm{~T}=25{ }^{\circ} \mathrm{C}\right.$ and $\left.\mathrm{DC}=36 \mathrm{~mA} / \mathrm{cm}^{2}\right)$. The using graphite electrode in water electrolysis as anode is not preferable as platinum electrode. The average efficiency of oxygen of graphite electrode is $77 \%$ while the efficiency reaches $100 \%$ in case of using platinum electrode. It noted that the volume of the gas increases as the current density rises from 6.6 to $31 \mathrm{~mA} / \mathrm{m}^{2}$ through time of $2 \mathrm{hrs}$ [2].

\section{Hydrogen Storage}

Energy carriers are an appropriate form of stored energy, electricity is one type of carrier that produce from different sources, transported over large distances, and distributed to the end user [62]. The opinion of human fuel evolution hydrogen is revealed to be the future fuel. The fuel evolution experienced the history from coal through petroleum to natural gas following the path of rising the amount of hydrogen, therefore, it must finally reaches the destination of pure hydrogen and find suitable mothed to storage the hydrogen as well [4]. The hydrogen method storage for subsequent use many attitudes, included high pressures, cryogenics, and chemical composites that reversibly rises $\mathrm{H}_{2}$ upon heating. Underground hydrogen storage is one of useful method for storing hydrogen, it is used to afford grid energy storage for renewable energy sources well as providing fuel for transportation, particularly for airplanes and ships. It can be storage in caverns, aquifers, depleted petroleum and natural gas fields, and man-made caverns affecting from mining and other action may be technologically possible. Most research focused on hydrogen storage as a lightweight, compact energy carrier for hydrogen cars and mobile application. Hydrogen also can be stored in a solid state by forming metal hydride (MH). The mechanism of formation metal hydride is that hydrogen molecules dissociate into $\mathrm{H}$ atoms that are inserted in interstitial spaces inside the lattice of alloys or intermetallic compounds [62]. Some of the metallic hydrides of interest for the storage purpose are used such as $\mathrm{LaNi}_{5} \mathrm{H}_{6}, \mathrm{ZrV}_{2} \mathrm{H}_{5}, \mathrm{CeNi}_{3} \mathrm{H}_{4}, \mathrm{Y}_{2} \mathrm{Ni}_{7} \mathrm{H}_{3}, \mathrm{Ho}_{6} \mathrm{Fe}_{23} \mathrm{H}, \mathrm{TiFeH}_{2}$, and $\mathrm{Mg}_{2} \mathrm{NiH}_{4}$. Metal hydrides can desorb hydrogen at room temperature and near the atmospheric pressure, and volumetric density of the hydrogen atoms exist in the host lattice is extremely high. A volumetric density of $115 \mathrm{~kg} / \mathrm{m}^{3}$ was reached in $\mathrm{LaNi}_{5} \mathrm{H}_{6}$. The gravimetric hydrogen density is limited to less than $3 \mathrm{wt} \%$, for example, the gravimetric density of hydrogen in $\mathrm{LaNi}_{5} \mathrm{H}_{6}$ is only 1.4. Currently attention turns to the hydrides formed by light metals and the most common of light metal is $\mathrm{Mg}$. The formation metal hydrides are considered as exothermic reaction. Heat is released by absorbing $\mathrm{H}_{2}$ on metal surface. The more stable hydride is, more heat is required to desorb $\mathrm{H}_{2}$. The quantity of energy around $25 \%$ higher than the heating value of hydrogen is required for the release of hydrogen from magnesium hydride [4]. Hydrogen store as fuel for road in vehicle tanks, liquid hydrogen tanker-bulk carrier and gaseous or liquid hydrogen truck trailer are used as Mobile storage systems for transport.

\section{Conclusion}

This report outlined major hydrogen production technologies. The production of hydrogen utilization must be accompanied by the equally viable technologies for hydrogen production, storage, transportation and distribution Although a majority of the above described hydrogen conversion technologies has already been developed and demonstrated, and most of them has a clear advantage over the existing technologies, hydrogen is not being used as a

Volume 6 Issue 7, July 2017 www.ijsr.net 


\section{International Journal of Science and Research (IJSR) \\ ISSN (Online): 2319-7064}

Index Copernicus Value (2015): 78.96 | Impact Factor (2015): 6.391

fuel on a large scale (except for the space programs). It is often possible to find another technology that may be either better, or less expensive, or more efficient or more convenient that can compare with the benefits that the hydrogen energy system offer. Resource of hydrogen energy is coal and biomass, oil, natural gas, algae and alcohols, water electrolysis, PV-electrolysis, wind -electrolysis and geothermal energy electrolysis. A focus was made production of hydrogen gas from naturel source, especially from water electrolysis. This study provides also basic information about effects on the efficiency of the electrolysis process such as concentration electrolyte, $\mathrm{pH}$, pressure, temperature electrical resistance of the electrolyte. Electrolyte conductions, separator material, effect of applied voltage and current and electrode material. The production of hydrogen as increased as increasing in electrolyte concentration. However, the concentration level of acidic and alkali solutions are restricted in practice because of the highly corrosive behaviour of some materials. Temperature is one of the most effective variables on the electric power demand of an electrolytic cell. Electrolysis method is much more efficient at raised temperatures.

\section{Acknowledgements}

The authors would like to extend their gratitude to wards a Faculty of Arts and Sciences, Kufra Campus, University of Benghazi, Al Kufrah, Libya the Libyan Academy Department of Energy Technology.

\section{References}

[1] Altork, L.N. \& Busby, J. R. "Hydrogen fuel cells: part of the solution" Technology \& Engineering Teacher, vol. 70(2), pp 22-27, 2010.

[2] Hegazy A. "Study and Development of Solar Hydrogen Production System” M.Sc. Thesis Faculty of Engineering, Cairo University Giza, Egypt.2005.

[3] Contreras A, Posso F, Veziroglu T. "Modeling and Simulation of the Production of Hydrogen Using Hydroelectricity in Venezuel" International Journal of Hydrogen Energy,; vol. 32, pp. 1219 - 1224, 2007.

[4] Zhou Li.. "Progress and problems in hydrogen storage methods Renewable and Sustainable Energy Reviews, Vol 9, pp. 395-408, .2005.

[5] Richard, S. "A Techno-Economic Analysis of Decentralized Electrolytic Hydrogen Production for Fuel Cell Vehicles" M.Sc., Thesis in the Department of Mechanical Engineering , University of Victoria. 2004.

[6] Ana A. "Highly Efficient Hydrogen Generation Via Water Electrolysis Using Nanometal Electrodes“" Energy Research Laboratory, Clean Energy and Power for Advance Energy, Quantum Sphere Inc: vol. 4, pp.545-626, 2006.

[7] Gaudernack B. Hydrogen Production from Fossil Fuels. In Hydrogen Power, Theoretical and Engineering Solutions, Proceedings of the Hypothesis II Symposium held in Grimstad, Norway, vol. 18, pp75-89, 1997.

[8] Rifkin, j.(2014); "the hydrogen economy opportunities costs barriers and r\&d needs", national research council and national academy of engineering of the national academies.

[9] Mazloomi A, Sulaiman, N, Moayedi, H. “ Electrical Impedance of Water Electrolysis Cells With a View to Saving Energy" International Journal of Electrochemical Scince, pp. 3466 -3481.2012

[10] Riis, T. and Hagen, E. 2006. Hydrogen Production and Storage, International Energy Agency, France.

[11] Andreass, K.Hydrogen "Production by Electrolysis Hydrogen Power: Theoretical and Engineering Solutions" Proceedings of the Hypothesis II Symposium held in Grimstad, Norway, vol.1, pp. 91102,1988

[12] Lipman T. An Overview of Hydrogen Production and Storage Systems with Renewable Hydrogen Case Studies Clean Energy. Hydrogen and Fuel Cell Resource Library, Report.2011.

[13] Kalinci, Y, Hepbasli A. "Biomass-based hydrogen production: A review and analysis" International Journal of Hydrogen Energy, vol 34(21), pp. 87998817. 2009.

[14] Wood B, Whitmore S, Ban H, Burnham B R. "Hydrogen Production Using Geothermal Energy" Utah state university Logan. M Sc., 2008.

[15] Li, F, Zeng L., Shih L. "Techno-Economic Analysis of Coal-Based Hydrogen and Electricity Cogeneration Processes with $\mathrm{CO}_{2}$ Capture" Industrial \& Engineering Chemistry Research.2010; vol. 49(21), pp.1101811028, 2010.

[16] Dodds P, McDowall W. "A review of Hydrogen Production Technologies for Energy System Models" UCL Energy Institute, University College London. 2012.

[17] Ogden, J. M. 2001.Review of small stationary reformers for hydrogen production. Princeton, USA, Princeton University.

[18] Wykoff D, John P, Anastasios D, Grossman A. R . "The Regulation of Photosynthetic Electron Transport during Nutrient Deprivation in Chlamydomonas reinhardtii "American Society of Plant Physiologists. 1998.

[19] Melis A, Zhang L, Forestier M, Ghirardi ML, Seibert M. "Sustained photobiological hydrogen gas production upon reversible inactivation of oxygen evolution in the green alga Chlamydomonas reinhardtii" Plant Physiol vol. 122, pp. 127-136, 2000.

[20] Deluga A, Schmidt L. "Production of Hydrogen from alcohols" Regents of the University of Minnesota. 2007.

[21] Mori M, Mržljak T, Drobnič B, Sekavčnik M. "Integral characteristics of hydrogen production in alkaline electrolysers" Journal mechanical engineering vol. 59(10), pp. 585-594,2013.

[22] Holladay J, King D, Wang Y. An overview of hydrogen production technologies. Production Symposium at the American Chemical Society. 2009; 139(4):244- 260.

[23] Turner, J.A., Deutsch, T., Head, J. and Vallett, P. 2007. Photoelectrochemical water systems for $\mathrm{H}_{2}$ production, DOE Hydrogen Program Annual Merit Review, U.S. Department of Energy, Washington, DC.

\section{Volume 6 Issue 7, July 2017 www.ijsr.net}




\section{International Journal of Science and Research (IJSR) \\ ISSN (Online): 2319-7064}

Index Copernicus Value (2015): 78.96 | Impact Factor (2015): 6.391

[24] Koroneos C, Dompros A, Roumbas G, Moussiopoulos $\mathrm{N}$. "Life cycle assessment for hydrogen fuel production processes" International Journal Hydrogen Energy;vol. 29, pp.1443-50, 2004.

[25] Bicakov O, Straka P. "The Resources and Methods of Hydrogen Production" Acta Geodyn Geometer vol.7(2), pp.175-188, 2010

[26] Miyake, J., Miyake, M., and Asada, Y. "Biotechnological hydrogen production: Research for efficient energy conversion" Journal of Biotechnology, vol. 70 pp.89-101.1999

[27] Huang R. Hydrogen production by photoelectrolysis. 2002.

http://bhuang02.tripod.com/photoelectrolysis.htm

[28] Liepa M A, Borhan A. "High-temperature steam electrolysis: Technical and economic evaluation of alternative process designs" International Journal of Hydrogen Energy, vol. 11 (7), pp. 435-442, 1986.

[29] Weber, M F, Dignam M J.. "Efficiency of splitting water with semiconducting photoelectrodes" Journal of Electrochemical Society, vol 131, pp 1258-1265, 1984

[30] Doenitz, W. Schmidberger, R. Steinheil, E. Streicher. R. "Hydrogen production by high temperature electrolysis of water vapour" International Journal of Hydrogen Energy, vol. (5)1, pp.55-63.1980.

[31] Abanades S. Charvin P, Flamant G. Neveu, R. "Screening of water-splitting thermochemical cycles potentially attractive for hydrogen production by concentrated solar energy" Energy, vol. 31, pp 28052822. 2006.

[32] Brown L C, Lentsch R D, Besenbruch G.E., Schultz K.R., Funk J.E. Alternative Flowsheets for the Sulphuriodine Thermochemical Hydrogen Cycle. Report Num. GA- A24266, GENERAL ATOMICS, 2003.

[33] Raissi A. Analysis of Solar Thermochemical WaterSplitting Cycles for Hydrogen Production. Hydrogen, Fuel Cells, and Infrastructure Technologies, FY. $2003 . \quad$ Progress Report. http://www.fsec.ucf.edu/en/research/hydrogen/analysis /documents/FY03_ProgressReport.

[34] Chen Z, Dinh H, Miller E. Photoelectrochemical Water Splitting: Standards, Experimental Methods, and Protocols.. Book published by Springer. 2013.

[35] Pickett P DJ. 1979. Electrochemical Reactor Design. Amsterdam: Elsevier,

[36] Oh J, Deutsch T, Yuan H, Branz H. "Nanoporous Black Silicon Photocathode for Hydrogen Production by Photoelectrochemical Water Splitting" Energy and Environmental Science, vol. 5(4), pp. 1690-1694, 2011.

[37] Jónsson V K, Gunnarsson R L, Árnason B, Sigfússon T I. "The feasibility of using geothermal energy in hydrogen production" Geothermics, vol. 21( 5-6), pp. 673-681, 1992.

[38] Turner, J.A., Deutsch, T., Head, J. and Vallett, P. 2007. Photoelectrochemical water systems for $\mathrm{H}_{2}$ production, DOE Hydrogen Program Annual Merit Review, U.S. Department of Energy, Washington, DC.

[39] Li S K, Furtak T, Brown L, Deutsch T, Turner J, Herring A. "Cobalt-Phosphate (Co-Pi) Catalyst Modified Mo-Doped $\mathrm{BiVO}_{4}$ Photoelectrodes for Solar
Water Oxidation" Energy and Environmental Science, vol. 12(4) pp. 5028-5034, 2011.

[40] Fujishima, A.K., K. Honda: "Electrochemical photolysis of water at a semiconductor electrode" Nature, vol. 238 (1972), pp.37-38. 2004.

[41] Abdel-Ala H, Zohdy K, Abdel Kareem M. "Hydrogen Production Using Sea Water Electrolysis" The Open Fuel Cells Journal.; pp 3:1-7, 2010.

[42] Yuvaraj Y, Santhanaraj D. "A systematic study on electrolytic production of hydrogen gas by using graphite as electrodec" Materials Research, Vol 17(1), 516-1439. 2014.

[43] Porciúncula, C. B., Marcilio N. R., Godinho M., Secchi A. R., "Fluid dynamics simulation for design of a biomass gasifier" Computer Aided Chemical Engineering, vol. 27, pp.1071-1076. 2009.

[44] Mahrous M,. Sakr, A, Balabel A, Ibrahim." Experimental Investigation of the Operating Parameters Affecting Hydrogen Production Process through Alkaline Water Elecergtrolysis" International Journal of Thermal and Environmental Engineering. vol. 2(2): pp.113-116, 2011.

[45] Jabar, S, Ibrahim M. "The Effect of $\mathrm{NaHCO}_{3}$ as Catalyst via Electrolysis" Natural Resources, vol. 4, pp. 65-68, 2013.

[46] Bennett JE 1980. "Electrodes for generation of hydrogen and oxygen from seawater" International Journal of Hydrogen Energy, vol. 5(4), pp 401-408.

[47] Abdallah S, Yousef E, Katab M, Abdullah I. " The Effect of PH on the Hydrogen and Oxygen Production Using Photovoltaic Power Generator IKSKS" International journal of Sustainable Water and Environmental Systems. vol. 5, pp 7-12, 2013.

[48] Ganley C J. "High temperature and pressure alkaline electrolysis" Intentional Journal Hydrogen Energy, vol. 34, pp3604-3611, 2009

[49] Nagai, N., M. Takeuchi, T. Kimura and T. Oka, "Existence of optimum space between electrodes on hydrogen production by water electrolysis" Intentional Journal Hydrogen Energy, vol 28(1), pp35-47, 2003.

[50] Appleby J, Crepy G, Jacquelin J. "High efficiency water electrolysis in alkaline solution" International Journal Hydrogen Energy, vol 3 (1), pp.2-37. 1978.

[51] Lipovestsky, V. "Production of Hydrogen Obtaining Electric and Thermal Energy by Water Dissociation Method" International Journal of Hydrogen Energy, vol. 29, pp. 1555-1558, 2004

[52] Roy L, Roy R, Wollen J, Stegner J, Harmon, M. Martin, S. Bodendorer , B. and Henson, I. "Calculation of the $\mathrm{pH}$ of Bufer Solution of 2[N-Morpholino] ethanesulfonic Acide (MES) from $5^{\circ} \mathrm{C}$ to $55^{\circ} \mathrm{C}$ " Open Journal of physical Chemistry, vol.1: pp.7-842011.

[53] Wei Z D, Ji M B, Chen S G, Liu Y, Sun C X, Yin G Z, Shen P K and Chan S H. "Water electrolysis on carbon electrodes enhanced by surfactant" Electrochim. Acta, vol. 52, pp 3323-3329, 2007.

[54] de Souza R F, Loget G, Padilha C J, Martini E M A, de Souza M O.. "Molybdenum electrodes for hydrogen production by water electrolysis using ionic liquid electrolytes" Ectrochemistry Communications, Vol.10, pp. 1673-.1675. 2008.

\section{Volume 6 Issue 7, July 2017 www.ijsr.net}




\section{International Journal of Science and Research (IJSR) \\ ISSN (Online): 2319-7064}

Index Copernicus Value (2015): 78.96 | Impact Factor (2015): 6.391

[55] Renaud R, RLeRoy. L. "Separator materials for use in alkaline water electrolysers" International journal Hydrogen Energy, vol. 7 (2), pp.155-166, 1982.

[56] Rosa V M, Santos M B F and da Silva E. P. "New materials for water electrolysis diaphragms" Intentional Journal of Hydrogen Energy. vol. 20(9), pp.697-700.1995

[57] Li S, Wang C, Chen C. "Water electrolysis for $\mathrm{H}_{2}$ production using a novel bipolar membrane in low salt concentration" Journal Member Science, vol. 330(1-2), pp. 334-340. 2009.

[58] Senftlea F E, Granta, b J R, Senftlec F P. ''Lowvoltage DC/AC Electrolysis of water using Porous Graphite Electrodes" Electrochimica Acta.Vol. 55(18), pp.5148-5153, 2010.

[59] Zeng k, Zhang D. "Recent progress in alkaline water electrolysis for hydrogen production and applications" Progress in Energy and Combustion Science, Vol 36(3), pp 307-326. 2010.

[60] Ranganathan S. "Carbon Promoted Water Electrolysis to Produce Hydrogen at Room Temperature" M. Sc. College of Engineering and Mineral Resources at West Virginia University, 2007.

[61] Kothari, R., D. Buddhi, R.L. Sawhney. "Optimization of electrolytic input power for the production of hydrogen" International Journal of Hydrogen Energy, vol. 31(15), pp. 2329-2336. 2006.

[62] Kreith F, Goswami Y. 2007. 27:1-15. Energy Efficiency and Renewable Energy, Hand Book of Energy Efficiency and Renewable Energy. Hydrogen Energy Technologies. 